\title{
Temperature and Moisture Dependence of the Specific Heat of High Performance Concrete
}

\begin{abstract}
J. Toman, R. Černý
The specific heat of two types of high performance concrete was measured in the temperature range from $20{ }^{\circ} \mathrm{C}$ to $1000{ }^{\circ} \mathrm{C}$ and in the moisture range from dry material to saturation water content. A nonadiabatic method was chosen instead of classical adiabatic treatments in order to meet the requirements following from the large representative elementary volume of the materials. The measured results reveal a significant temperature effect on the specific heat value. The influence of moisture is less important than the influence of temperature, but is also not negligible.
\end{abstract}

Keywords: concrete, specific heat, moisture content, temperature.

\section{Experimental determination of specific heat}

Application of classical adiabatic-calorimetry methods in measuring the specific heat of building materials can lead to certain difficulties for the following reasons:

a) The samples of building materials have to be relatively large because of their inhomogeneity

b) Due to the low thermal conductivity of most building materials it can take a relatively long time to reach temperature equilibration over large dimensions, resulting in significant heat loss.

Therefore, a nonadiabatic method was used for determining the temperature-dependent specific heat (see [1], for details).

The nonadiabatic calorimeter that we used has a mixing vessel with a volume of 2,5 liters. The volume of the measuring fluid (water in this case) is about 1 liter. The maximum volume of the measured samples is 1 liter. The amount of heat loss of the nonadiabatic system is determined using a calibration. The calorimeter is filled with water, whose temperature is different from the ambient air. Then, the relation of water temperature to time, $T_{c}(t)$, is measured.

The tests show that the calibration curve $T_{c}(t)$ is nearly exponential; small differences in measuring conditions cause only small changes in the calibration curve. The experiments have a replicability better than $1 \%$.

The measuring method itself is based on well-known principles. The sample is heated to a predetermined temperature $T_{s}$ in a muffle furnace and then put into the calorimeter with water. Then, the relation of water temperature to time $T_{w}(t)$ is measured, the water being slowly stirred all the time, until the temperatures of the measured sample and the calorimeter are equal. The duration of temperature equilibration ranges from 20 minutes to 1 hour, depending on the thermal conductivity and size of the material being measured.

The heat balance of the sample-calorimeter system can be written in the form:

$$
m c\left(T_{s}-T_{e}\right)=\left(K+m_{w} c_{w}\right)\left(T_{e}-T_{w 0}\right)+\Delta m \cdot L-Q_{r},
$$

where $m$ is the mass of the sample, $T_{s}$ is the temperature of the sample prior to being put into the calorimeter, $c$ is the specific heat of the sample in the temperature interval $\left[T_{e}, T_{s}\right], K$ is the heat capacity of the calorimeter, $m_{w}$ is the mass of the water, $c_{w}$ is the specific heat of water, $T_{w 0}$ is the initial water temperature, $L$ is the latent heat of evaporation of water, $Q_{r}$ is the reaction heat, $\Delta m$ is the mass of evaporated water,

$$
\Delta m=m+m_{c w}-m_{s}-\Delta m_{N}-\Delta m_{s c},
$$

$m_{c w}$ is the mass of the calorimeter with water before the measurement, $m_{s}$ is the mass of the system calorimeter-water-sample after measurement, $\Delta m_{N}$ is the mass of the water naturally evaporated during the measurement (this heat loss is already included in the heat loss calibration curve), $\Delta m_{s c}$ is the change of mass due to the chemical reaction of the sample with water (e.g., hydrolysis). This value can be obtained as $\Delta m_{s c}=m-m_{D}$, where $m_{D}$ is the mass of the dried sample after the measurement.

Determining the specific heat $c$ directly from equation (1) we would obtain a mean value of specific heat, $\bar{c}$, in the interval $\left[T_{e}, T_{s}\right]$ by

$$
\bar{c}=\frac{\left(K+m_{w} c_{w}\right) \cdot\left(T_{e}-T_{w 0}\right)+\Delta m \cdot L-Q_{r}}{m\left(T_{s}-T_{e}\right)} .
$$

However, from the physical point of view, it is more correct to determine the value of the specific heat "pointwise", in accordance with the definition of specific heat,

$$
c\left(T_{i}\right)=\left(\frac{\partial h}{\partial T}\right)_{T_{i}},
$$

where $h$ is the specific enthalpy.

Using relation (4) to determine specific heat, we have to specify the zero-point of the enthalpy scale, i.e., we have to ensure that all the enthalpy calculations are related to a certain constant temperature. This reference temperature can be, for example, $T_{k}=0{ }^{\circ} \mathrm{C}$. Upon adding

$$
Q=m \cdot c_{0} \cdot\left(T_{e}-T_{k}\right),
$$

where $c_{0}$ is the mean specific heat of the sample in the temperature interval $\left[0, T_{e}\right]$, to both sides of equation (1), and dividing by $m$, we obtain

$$
h\left(T_{s}\right)=\frac{\left(K+m_{w} c_{w}\right)\left(T_{e}-T_{w 0}\right)+\Delta m \cdot L-Q_{r}}{m}+c_{0}\left(T_{e}-T_{k}\right) .
$$

The value of $c_{0}$ is considered to be constant, taking into account the condition

$$
T_{s}-T_{e}>T_{e}-T_{k},
$$


and it can be measured, for example, using the classical adiabatic method.

Performing a set of measurements for various sample temperatures $T_{i}$, we obtain a set of points $\left[T_{i}, h\left(T_{i}\right)\right]$. A regression analysis of this pointwise given function results in a functional relationship for $h=h(T)$ and, using relation (4), also in the function $c=c(T)$ as the first derivative of $h$ with respect to $T$.

\section{Materials and samples}

The experimental work was done with two types of high performance concrete used in nuclear power plants: Penly concrete and Temelin concrete.

Penly concrete was used for concrete containment building in a nuclear power plant in France (samples were obtained from M. Dugat, Bouygues Company, France). It had a dry density of $2290 \mathrm{~kg} / \mathrm{m}^{3}$, and consisted of the following components: Cement CPA HP Le Havre $\left(290 \mathrm{kgm}^{-3}\right)$, sand 0/5 size fraction $\left(831 \mathrm{kgm}^{-3}\right)$, gravel sand $5 / 12.5$ size fraction $\left(287 \mathrm{kgm}^{-3}\right)$, gravel sand 12.5/25 size fraction $\left(752 \mathrm{kgm}^{-3}\right)$, calcareous filler PIKETTY $\left(105 \mathrm{kgm}^{-3}\right)$, silica fume $\left(30 \mathrm{kgm}^{-3}\right)$, water $\left(131 \mathrm{kgm}^{-3}\right)$, retarder CHRYTARD 1.7 , super-plasticizer Resine GT 10.62. The maximum water saturation was $4 \% \mathrm{~kg} / \mathrm{kg}$.

The Temelin concrete used for the concrete containment building of the Temelin nuclear power plant in the Czech Republic had a dry density of $2200 \mathrm{~kg} / \mathrm{m}^{3}$ and maximum water saturation $7 \% \mathrm{~kg} / \mathrm{kg}$. The composition was as follows: Cement 42.5 R Mokrá (499 $\mathrm{kgm}^{-3}$ ), sand 0/4 size fraction $\left(705 \mathrm{kgm}^{-3}\right)$, gravel sand $8 / 16$ size fraction $\left(460 \mathrm{kgm}^{-3}\right)$, gravel sand $16 / 22$ size fraction $\left(527 \mathrm{kgm}^{-3}\right)$, water $\left(215 \mathrm{kgm}^{-3}\right)$, plasticizer $4.5 \mathrm{~lm}^{-3}$.

The specimens for measuring the specific heat were cubic in shape, $71 \times 71 \times 71 \mathrm{~mm}$ for both materials. Twenty measurements were made for each material.

\section{Measured results}

\subsection{Temperature dependence of specific heat}

The measured results are summarized in Figs. 1a, b. In the temperature range to $400{ }^{\circ} \mathrm{C}$, both materials behaved in a similar way, and we observed a characteristic increase of specific heat with temperature. The measured data were very close to those determined earlier for similar concrete mixes [2]. For temperatures above $400^{\circ} \mathrm{C}$, the specific heat of Temelin concrete slowed down its increase with temperature, and for temperatures higher than $600{ }^{\circ} \mathrm{C}$ the specific heat began to decrease. These changes in the character of the specific heat vs. temperature relation can be explained by structural changes of the material in this temperature range, which are due to the loss of crystallically bonded water and dehydration of some components. The Penly concrete was found (from the point of view of structural changes) to be more stable against high temperature exposure. The specific heat vs. temperature relation remained increasing in the whole studied temperature range, only the increase was slower for temperatures above $400{ }^{\circ} \mathrm{C}$.

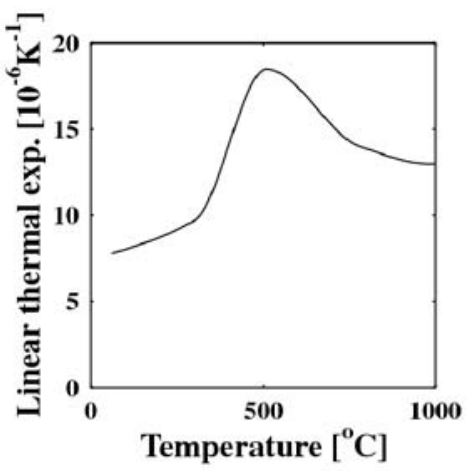

Fig. 1a: Dependence of the specific heat of Temelin concrete on temperature

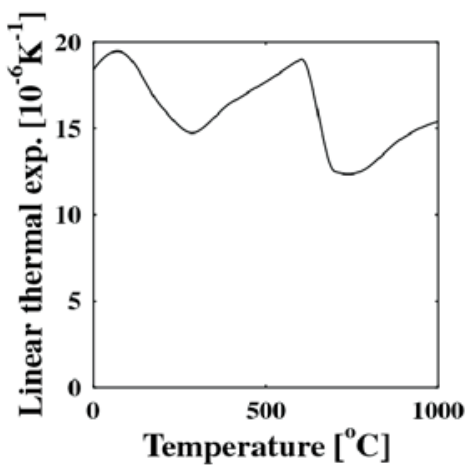

Fig. 1b: Dependence of the specific heat of Penly concrete on temperature

\subsection{Moisture dependence of specific heat}

The measured results showed that the sensitivity of the nonadiabatic method was not high enough to distinguish between the changes of specific heat due to the moisture variation in the whole range of moisture; only the differences between the dry samples and the samples with very high moisture content could be distinguished in a reliable way. The comparative experiments with the classical adiabatic method gave very similar results; again no reliable data were obtained.

Therefore, we employed a classical superposition principle of water and dry material and calculated the specific heat according to the analytical formula given by I. Kašpar [3]:

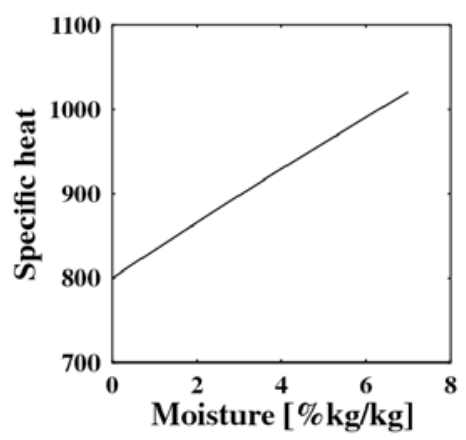

Fig. 2a: Dependence of the specific heat of Temelin concrete on the moisture content 


$$
c=\frac{c_{d}+c_{w} \cdot u / 100}{1+u / 100}
$$

where $c_{d}$ is the specific heat of the dry material, $c_{w}$ the specific heat of water, $u$ the moisture in $\% \mathrm{~kg} / \mathrm{kg}$.

The results for the temperature $25{ }^{\circ} \mathrm{C}$ calculated according to this formula are shown in Figs. $2 \mathrm{a}, \mathrm{b}$.

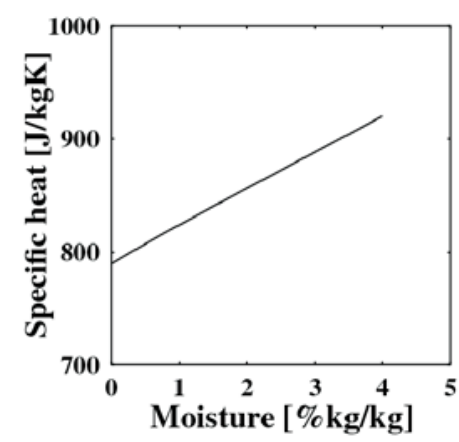

Fig. 2b: Dependence of the specific heat of Penly concrete on the moisture content

\section{Conclusions}

The specific heat of two types of high performance concrete was determined in wide temperature and moisture ranges. The temperature dependence was found to be very important. Compared to the room temperature data, we observed changes within the range of several tens of percent, and for the case of Penly concrete the value at $1000{ }^{\circ} \mathrm{C}$ was even approximately two times higher than at $100{ }^{\circ} \mathrm{C}$. The moisture dependence of specific heat was not found to be as remarkable as the temperature dependence, but the changes of the specific heat in the range of approximately $10 \%$ compared to the dry material were also not negligible as well.

\section{Acknowledgement}

This paper is based on work supported by the Ministry of Education of the Czech Republic, under contract No. CEZ:J04/98:210000003.

\section{References}

[1] Toman, J., erný, R.: High Temp.-High Press. 25 (1993), p. 643

[2] Toman, J.: Influence of External Conditions on Building Materials and Structures (in Czech). Thesis, CTU Prague 1986

[3] Kašpar, I.: Moisture Transport in Building Materials (in Czech). Thesis, CTU Prague 1984

Prof. Mgr. Jan Toman, DrSc.

Department of Physics

phone: +420224354694

e-mail: toman@fsv.cvut.cz

Prof. Ing. Robert Černý, DrSc.

Department of Structural Mechanics phone: +4202 24354429

e-mail: cernyr@fsv.cvut.cz

CTU, Faculty of Civil Engineering

Thákurova 7, 16629 Prague 6

Czech Republic 